\title{
RIVEC (Rejection, Intimacy, Values, Emotions, and Culture) Prejudice Scale: An Adaptation to the Chilean Context of the Blatant and Subtle Prejudice Scale
}

\author{
Hector Arancibia Martini, ${ }^{1}$ Amalio Blanco, ${ }^{2}$ Miguel Á. Ruiz, ${ }^{2}$ and Manuel Cárdenas Castro ${ }^{3}$ \\ ${ }^{1}$ Facultad de Humanidades, Universidad de Valparaíso, Valparaíso, Chile \\ 2 Department of Social Psychology and Methodology, Universidad Autónoma de Madrid, Madrid, Spain \\ ${ }^{3}$ Escuela de Psicología, Universidad de Valparaíso, Valparaíso, Chile
}

\begin{abstract}
$\mathrm{B}$ ased on Pettigrew and Meertens' Blatant and Subtle Prejudice Scale (1995), a new scale for assessing the expression of prejudice is proposed in this article. The original scale has been changed in three ways: (a) items were rewritten to avoid double assertions, (b) three new items were considered to adequately measure the 'denial of positive emotions' component, and (c) biased wording of the 'cultural differences' domain items measuring perceived cultural differences rather than prejudices was removed. We used a representative sample of 500 participants living in Antofagasta, in Chile. Confirmatory factor and a hierarchical regression analyses support the proposed new scale. This instrument provides two measures: one general measure related to the intensity of prejudice expression and a second measure indicating the presence or absence of prejudice for each component type (Rejection, Intimacy, Values, Emotions, and Culture). The scale was confirmed for both genders; $45.2 \%$ of the participants scored a medium-high to extremely high expression of prejudice towards Bolivians immigrants.
\end{abstract}

Keywords: blatant and subtle prejudice, prejudice typology, prejudice expression components, prejudice assessment

Throughout the 1870s, thousands of Chilean workers arrived in the coastal, sparsely populated Bolivian Antofagasta region to work for mostly Chilean, British, and American mining interests extracting saltpeter and other minerals; little Bolivian labour was recruited from the highlands. In 1879, when the Bolivian government sought to raise royalty rates, Chile seized the territory. Today, many Bolivians come to the once again booming, now long Chilean Antofagasta region, seeking opportunity.

Despite progress against discrimination and social exclusion, intense bias still exists in the world, and stereotyping, prejudice and discrimination persist (Fiske, 2012), affecting 'the lives of people in subtle but significant ways' (Dovidio, 2001, p. 834). Expressions of prejudice are becoming more subtle but no less damaging. Such prejudice is encountered, for instance, by persons exposed to subtle prejudice, whose self-esteem is severely affected by increasing internal attributions of failure (Crocker \& Major,
1989; Mayor, Quinton, \& Schmader, 2003; Operario \& Fiske, 2001).

More than 60 years ago, Allport noted that the expression of prejudice only occasionally takes the form of violent action, owing to internal and external controls that hinder its overt expression (Allport, 1954). Relying on this idea, Meertens and Pettigrew (1997, p. 57) proposed a distinction between blatant prejudice (an open and direct means of expressing prejudice) and subtle prejudice (an ostensibly politically correct and socially acceptable means of expressing prejudice). The authors operationalised these concepts using 20 items with five factors; two related to blatant prejudice (rejection [6 items] and intimacy [4 items]) and three related to subtle prejudice (values [ 4 items], culture [4 items], and emotions [2 items]; see Meertens \& Pettigrew, 1997; Pettigrew \& Meertens, 1995, 2001).

Pettigrew and Meertens' Blatant and Subtle Prejudice Scale has been widely applied in different cultural 
contexts (e.g., Cárdenas, 2010; Hightower, 1997; Olaizola, Díaz, \& Ochoa, 2014; Ratazzy \& Volpato, 2003; Yoo, Steger, \& Lee, 2010; Zick, Wagner, Van Dick, \& Petzel, 2001) and is still frequently used in various social science fields.

However, beyond the unquestionable contribution of Pettigrew and Meertens (1995, 2001; also see Meertens \& Pettigrew, 1997), some weaknesses have been described: (a) the medium-high correlation between the two scales raised doubts regarding the existence of two different types of prejudice (Coenders, Scheepers, Sniderman, \& Verbek, 2001; Espelt, Javaloy, \& Cornejo, 2006; Hamberger \& Hewstone, 1997; Ratazzi \& Volpato, 2003; Rueda \& Navas, 1996); (b) high scores for 'cultural differences' indicate perceived cultural differences of the outgroup but do not necessarily indicate discrimination based on such differences (Coenders et al., 2001); (c) the factor structure of the scale does not confirm the authors' original proposal (Coenders et al., 2001; Espelt et al., 2006; Gómez \& Huici, 1999; Hamberger \& Hewstone, 1997; Rodriguez Díaz, Herrero Olaizola, Ovejero Bernal, \& Torres, 2009; Rueda \& Navas, 1996; Villano, 1999); (d) there are noteworthy problems related to the structuring and wording of some of the items; and (e) the measurement of the 'emotion' component with only two items affects the reliability and local identification of this factor (Byrne, 2013).

In order to overcome the limitations previously described, and with the aim of measuring the prejudice expression in a Latin American context (i.e., prejudice towards Bolivian immigrants in Chile), we propose an adaptation of the original scale that could be suitable for measuring current forms of prejudice expression: the Rejection, Intimacy, Values, Emotions, and Culture Prejudice Scale (RIVEC; see Appendix). The original scale has been modified in three main ways: (a) items were rewritten to avoid double assertions; (b) according to Brown's (2006) recommendation for a confirmatory factor analysis (CFA) strategy, three items were considered to measure adequately the 'denial of positive emotions' component (this factor was originally assessed with only two items); and (c) new items for the 'cultural differences' domain were posed to avoid the biased wording of the original items, which actually assessed perceived cultural differences rather than prejudice (e.g., 'If my son had a Bolivian [target group] classmate, he would be enriched by recognising different traditions and customs' [new proposed] rather than 'How different or similar do you think Turks [target group] living here are to other Dutch people like yourself [very different, somewhat different, somewhat similar, or very similar] in the language that they speak?' [original item]).

In accordance with Pettigrew and Meertens (1995), we agree that current prejudice could be assessed through the five components originally proposed: threat and rejection (Rejection), loss of intimacy (Intimacy), traditional values (Values), denial of positive emotions (Emotions), and cultural differences (Culture). However, according to empirical evidence, there are two issues to which we must pay attention. First, because of the high correlation between the blatant and subtle dimensions reported in previous publications, the five dimensions cannot be assigned in advance to a blatant or subtle prejudice category and consequently cannot distinguish between blatant, subtle, and equalitarian participants. The five components could be used to calculate a general measure of prejudice that would refer more to the intensity of prejudice expression than to the type of person who expresses it, as in Pettigrew and Meertens' scale. Thus, the presence or absence of prejudice is indicated, based on the five components. As a whole, the scale provides a generalised measure of intensity of expressed prejudice. Second, the reason that participants respond in a blatant, subtle, or equalitarian manner is modulated by the social context more than by the participants' individual dispositions. The expressions of subtle and blatant attitudes are possibly not as stable as Pettigrew and Meertens (2001) suggested. Rather, such expressions are caused by the target prejudice group and the social context of relationships. Thus, as with any other attitude, the expression of prejudice and its intensity may also vary to some extent within the same person, depending on the context in which the prejudice occurs (Allport, 1954; Bobo \& Fox, 2003; Sherif, 1967; Tajfel, 1982). Similar to the statement regarding stereotypes from Hilton and von Hippel (1996, p. 238), it can be asserted that prejudice 'emerges in various contexts to serve particular functions necessitated by those contexts'. Prejudice is an attitude in context: 'because prejudice exists at the intersection of group stereotypes and the requirements of social roles, it is fundamentally responsive to social context' (Eagly \& Diekman, 2005, p. 31).

In short, we propose the existence of a general dimension of prejudice common to all items (similar to a general factor in models of personality) and five specific components in which prejudice can be expressed independently with different levels of intensity (similar to specific personality factor models; e.g., Big Five personality factors). Thus, the aims of this article are to propose a shorter, adapted instrument for the Chilean context of the Pettigrew and Meertens Blatant and Subtle Prejudice Scale (1995) that overcomes some of the technical limitations of the original scale, and to assess the intensity of the current expression of prejudice by Chileans towards Bolivian immigrants.

\section{Method \\ Participants and Procedure}

All participants were interviewed after approving and signing the informed consent, which guaranteed anonymity. The data collection was conducted by a team of professional interviewers who visited the respondents in their homes, told them that the study was part of a research project on perceptions of a certain social 
Table 1

Sociodemographic Characteristics and Descriptive Analysis of Quantitative and Categorical Variables With Four or More Categories

\begin{tabular}{|c|c|c|c|c|c|c|c|}
\hline \multirow[b]{2}{*}{ Variable } & \multicolumn{7}{|c|}{ Total sample $(n=471)$} \\
\hline & $N^{*}$ & $\%$ & Mean** & Variance ${ }^{* *}$ & $D T^{* *}$ & Skewness** & Kurtosis** \\
\hline \multicolumn{8}{|l|}{ Gender } \\
\hline Women & 233 & 49.5 & & & & & \\
\hline Men & 238 & 50.5 & & & & & \\
\hline Age & & & 38.4 & 279.7 & 16.7 & 0.8 & -0.3 \\
\hline \multicolumn{8}{|l|}{ Religious beliefs } \\
\hline Yes & 303 & 64.5 & & & & & \\
\hline No & 167 & 35.5 & & & & & \\
\hline \multicolumn{8}{|l|}{ Ethnic minority membership } \\
\hline Yes & 37 & 7.9 & & & & & \\
\hline No & 432 & 92.1 & & & & & \\
\hline Household educational level & & & 4.77 & 2.1 & 1.5 & -0.6 & -0.04 \\
\hline $\begin{array}{l}\text { Incomplete primary } \\
\text { Education }\end{array}$ & 16 & 3.4 & & & & & \\
\hline Primary education & 22 & 4.7 & & & & & \\
\hline Incomplete secondary & 40 & 8.5 & & & & & \\
\hline Education & & & & & & & \\
\hline Secondary education & 113 & 24 & & & & & \\
\hline $\begin{array}{l}\text { Technical education or } \\
\text { incomplete higher education }\end{array}$ & 106 & 22.6 & & & & & \\
\hline Bachelor's degree & 130 & 27.7 & & & & & \\
\hline Postgraduate & 43 & 9.1 & & & & & \\
\hline Political self-categorization & & & 2.9 & 0.6 & 0.8 & 0.1 & -0.3 \\
\hline Extreme left-wing & 8 & 1.7 & & & & & \\
\hline Left-wing & 130 & 27.9 & & & & & \\
\hline Center & 228 & 48.9 & & & & & \\
\hline Right-wing & 93 & 20 & & & & & \\
\hline Extreme right-wing & 7 & 1.5 & & & & & \\
\hline Immigrants rights & & & 1.87 & 0.9 & 0.9 & 0.6 & -0.9 \\
\hline Extend & 220 & 47.1 & & & & & \\
\hline Maintain & 110 & 23.6 & & & & & \\
\hline Restrict & 115 & 24.6 & & & & & \\
\hline Abolish & 22 & 4.7 & & & & & \\
\hline
\end{tabular}

Note: *The total $n$ of some variables are lower than 471 because of the missing data; **It is reported the mean, variance, standard deviation, skewness, and kurtosis of the quantitative variable 'age' and for ordinal variables of 4 or more categories.

group living in the region, and provided instructions for completing the form (which included a self-assessment section and a section completed by the interviewer based on the notes that s/he took during the interview). A map of the assigned area showing the route to be followed, and the blocks and houses selected were given to the interviewer. A total of 500 participants were recruited for the study, and their ages ranged from 18 to 65 years old. All participants were living in the Antofagasta region of Chile. A probabilistic sample was selected using a double-stage sampling method: (1) cluster sampling (census districts), and (2) simple random sampling. A 95\% confidence interval was used for the estimates, and a 5\% sampling error was assumed. The final sample (Table 1), after listwise deletion due to the omission of answers in the items of the scale, was composed of 471 Chilean participants (94.2\%); $49.5 \%$ were women $(n=233)$ with a mean age of 38.3 years $(S D$ $=13.73)$ and $50.5 \%$ were male $(n=238)$ with an average age of 38.29 years $(S D=16.89)$. Most of the sample self-identified as holding religious belief (64.5\%), not belonging to an ethnic minority (92.1\%), and as having a technical or higher educational level (59.4\%). Very nearly a majority (i.e., dominant modal portions) self-identified as having a centrist political orientation (48.9\%) and with a tendency to support the extension of immigrant rights $(47.1 \%)$.

\section{Instrument}

The applied instrument (see Appendix: RIVEC Prejudice Scale) was theoretically structured in five dimensions in accordance with Pettigrew and Meertens' (1995) original components: 'Threat and rejection' (Rejection: three items), 'Loss of intimacy' (Intimacy: three items), 'Defence of traditional values' (Values: three items), 'Denial of positive emotions' (Emotions: three items), and 'Cultural differences' (Culture: three items). But some changes were implemented: (a) we used as a base the Spanish version of the Pettigrew and Meertens Blatant and Subtle Prejudice Scale validated in Chile by Cárdenas (2010); (b) three items were considered to measure each of the 5 components (generating balance in the measure of each of the factors and with the purpose to avoid the possible interference of spurious items, which could introduce lack-of-fit or estimation problems); (c) we rewrote many items to solve problems related to item phrasing (Arancibia, Ruiz, 
Blanco, \& Cárdenas, 2016); (d) items in this new scale were originally created in Spanish and accounted for the cultural characteristics of the applicable context; (e) the instrument was applied in the Spanish version as participants of the sample were Chilean (i.e., Spanish speakers).

Thus, the underlying factorial model of this 15-item version proposes the existence of a general prejudice (a single second-order factor) measured by five components (Rejection, Intimacy, Values, Emotion, and Culture) affecting all questionnaire items. First-order cross-loadings were fixed to zero (the indicators measure only one of the first-order components). Hence this instrument considered Pettigrew and Meertens blatant and subtle theory but also the criticism raised by some authors regarding the psychometric problems of the original scale and the existence of two types of prejudice (Coenders et al., 2001; Devine, Monteith, Zuwerink, \& Elliot, 1991; Sniderman \& Tetlock, 1986; Sniderman, Piazza, Tetlock, \& Kendrick, 1991).

Bolivian immigrants were used as the referenced outgroup. The respondents indicated their level of agreement with each item on a 5-point Likert scale $(1=$ totally disagree, $2=$ disagree, $3=$ neither agree nor disagree, $4=$ agree, and $5=$ totally agree).

\section{Data Analysis}

Item analysis was performed first (the response frequency by category, the number of missing values, and descriptive statistics for each individual item). Reliability was assessed with internal consistency using ordinal alpha $(\alpha)$ according to Gadermann, Guhn, and Zumbo's (2012) recommendations for treating ordinal data. Nunnally and Bernstein's (1994) criteria were used as a reference: $0.70<\alpha$ $<0.80$ indicated acceptable reliability and $\alpha>0.80$ indicated good reliability. Univariate normality was checked using the statistical indicators of skewness $\left(-2<G_{1}<2\right)$ and kurtosis $\left(-7<G_{2}<7\right)$ (Russell, 2002).

To assess the factor structure, CFA techniques were used. Considering that there were few respondents whose data were missing from the sample $(n=29)$ and with the purpose of using the same cases in the hierarchical regression analyses, as recommended by Brown (2006), a listwise strategy was used for handling missing values. As a result, we were able to use an effective sample of 471 cases ( $94.2 \%$ of the total sample). The effective sample was randomly divided into two subsamples: subsample 1 ( $n=$ $236)$ and subsample $2(n=235)$. With subsample 1 we estimated two models: model 1, a hierarchical model with two correlated second-order factors (Blatant and Subtle) and five first-order factors (rejection and intimacy corresponding to blatant prejudice; and values, emotions, and culture factors corresponding to subtle prejudice); and model 2: a hierarchical model with one second-order factor (prejudice) and five first-order factors (Rejection, Intimacy, Values, Culture, and Emotions). Model 1 is justified because it accurately represents the theory developed by the original authors, where two forms of expression (blatant and subtle) compose prejudice. Model 2 partially represents Pettigrew and Meertens' theory. It considers the five dimensions (rejection, intimacy, values, culture, and emotions) but returns a general factor of prejudice, avoiding the distinction between blatant and subtle prejudice. Model 2 is justified because previous studies, in different cultural contexts, have not been entirely consistent with the distinction between blatant and subtle prejudice due to the high correlation among the blatant and subtle second-order factor structure (Cárdenas, 2010; Coenders et al., 2001; Gómez \& Huici, 1999; Hamberger \& Hewstone, 1997; Ratazzi \& Volpato, 2001; Ratazzi \& Volpato 2003; Rodríguez et al., 2009; Rueda \& Navas, 1996; Villano, 1999). The following goodness of fit (GOF) indices were considered to evaluate the model: absolute fit $\left(\chi^{2}, \chi^{2} / d f\right)$, parsimonious fit (RMSEA and SRMR), and comparative fit (CFI and TLI). We used the GOF cut-off criteria suggested by Marsh, Hau, and Wen (2004); Schreiber, Nora, Stage, Barlow, and King (2006); and Yu (2002): $\chi^{2} / d f<3$, CFI $>.95$, TLI $>.95$, SRMR $<.08$, and RMSEA $<.08$.

Finally, with the aim of assessing the relation between the construct measured by the RIVEC Prejudice Scale and other variables that have been traditionally related to prejudice in the literature (construct validity), hierarchical regression analyses (backward method) were carried out to identify whether sociodemographic and sociological characteristics of the participants were able to explain the scores on the RIVEC Prejudice Scale. Initially, the following independent variables were included in the model: 'immigrant rights' (ordinal variable: extend $=1$; maintain $=2$; restrict $=3$; and abolish $=4$ ), 'religious beliefs' (dichotomous variable: $n o=0$; and yes $=1$ ), 'ethnic minority membership' (dichotomous variable: not belonging $=0$; and belonging $=1$ ), 'political self-categorisation' (ordinal variable: extreme left-wing $=1$; left-wing $=2$; centre $=$ 3 ; right-wing $=4$; and extreme right-wing $=5$ ), 'gender' (dichotomous variable: female $=0$; and male $=1$ ), 'household educational level' (ordinal variable: incomplete primary education $=1$; complete primary education $=2$; incomplete secondary education $=3$; complete secondary education $=4$; technical education or incomplete higher education $=5$; bachelor's degree $=6$; and postgraduate studies $=7$ ), and 'age' (quantitative variable).

Statistical analyses were conducted using IBM SPSS v.21 statistical software. Confirmatory model estimations and multigroup analyses were performed using Amos v. 20.

\section{Scoring and Classification}

Individuals were scored in the first-order dimensions (corresponding to prejudice components) and the secondorder dimensions (corresponding to general prejudice levels) using factor score weights.

Maintaining the correction system proposed by the original authors, a raw score greater than or equal to $50 \%$ 
Table 2

Correlation Matrix for the Scales

\begin{tabular}{lllllll}
\hline Subscale & Rejection & Intimacy & Values & Emotions & Culture & Prejudice $^{1}$ \\
\hline Rejection & 1 & & & & & \\
Intimacy & $.58^{* *}$ & 1 & & & & \\
Values & $.64^{* *}$ & $.52^{* *}$ & $.55^{* *}$ & $.38^{* *}$ & 1 & \\
Emotions & $.49^{* *}$ & $.56^{* *}$ & $.47^{* *}$ & $.51^{* *}$ & 1 & 1 \\
Culture & $.51^{* *}$ & $.82^{* *}$ & $.78^{* *}$ & $.72^{* *}$ & $.77^{* *}$ & 1 \\
Prejudice & $.83^{* *}$ & & & & & \\
\hline
\end{tabular}

Note: ${ }^{1} 15$-item scale; ${ }^{* *} p<.001$

of the total possible score in a component was interpreted as evidence of the presence of prejudice expressed in that component. An intensity index was developed by summing the number of components in which each individual obtained a high score. Thus, the intensity score ranged from ' $0 c^{\prime}$ ( 0 components $\geq 50 \%$ ) to ' $5 c$ ' ( 5 components $\geq$ $50 \%$ ). Whereas Pettigrew and Meertens (1995) proposed fourfold classification criteria as a guide towards characterologic profiling (bigot, equalitarian, subtle, and error), new unidimensional profiling based on the intensity of prejudice is proposed. Thus, the intensity and presence of the expression of prejudice could be grouped into six categories: (a) 'absence' of prejudice in the five components, 0c; (b) 'low intensity' - presence of prejudice in 1 of five components, 1c; (c) 'low-medium intensity' - presence in two components, $2 \mathrm{c}$, (d) 'medium-high intensity' presence in three components, 3c; (e) 'high intensity' presence in four components, 4c; and (f) 'extreme intensity' - presence in all five components, $5 \mathrm{c}$.

\section{Results}

\section{Item Analysis, Reliability, and Correlation Between Scales}

The distribution of responses to the questionnaire items showed adequate fit with univariate normality. Skewness values ranged from 0.12 to $1.32(S E=0.11)$, and kurtosis values ranged from -1.09 to $1.18(S E=0.23)$.

Regarding the response patterns, the responses were adequately distributed, covering all response options for all items. No ceiling or floor effects were observed. The percentage of omissions was low, ranging from $0 \%$ to $0.8 \%$. The reliability coefficient for the total scale $(\alpha=.88)$ and for the Rejection subscale was good $(\alpha=.81)$ and acceptable for Intimacy $(\alpha=.73)$ and Values $(\alpha=.75)$ scales. The Emotions subscale was slightly under the expected limits $(\alpha=.69)$, and the Culture subscale presented the lowest reliability within the subscales $(\alpha=.61)$. Regarding the correlations (Table 2) between components, and between components and the overall prejudice scale, they were all statistically significant $(p<.001)$, being in the middle-high range. The lowest correlation was between the component 'values' and 'emotions' $(\phi=.38)$ and the highest among the components 'values' and 'reject' $(\phi=$ .64). The correlations between the total scale (prejudice) and components ranged from $\phi=.72$ ('emotions') to $\phi=$ .83 ('rejection').

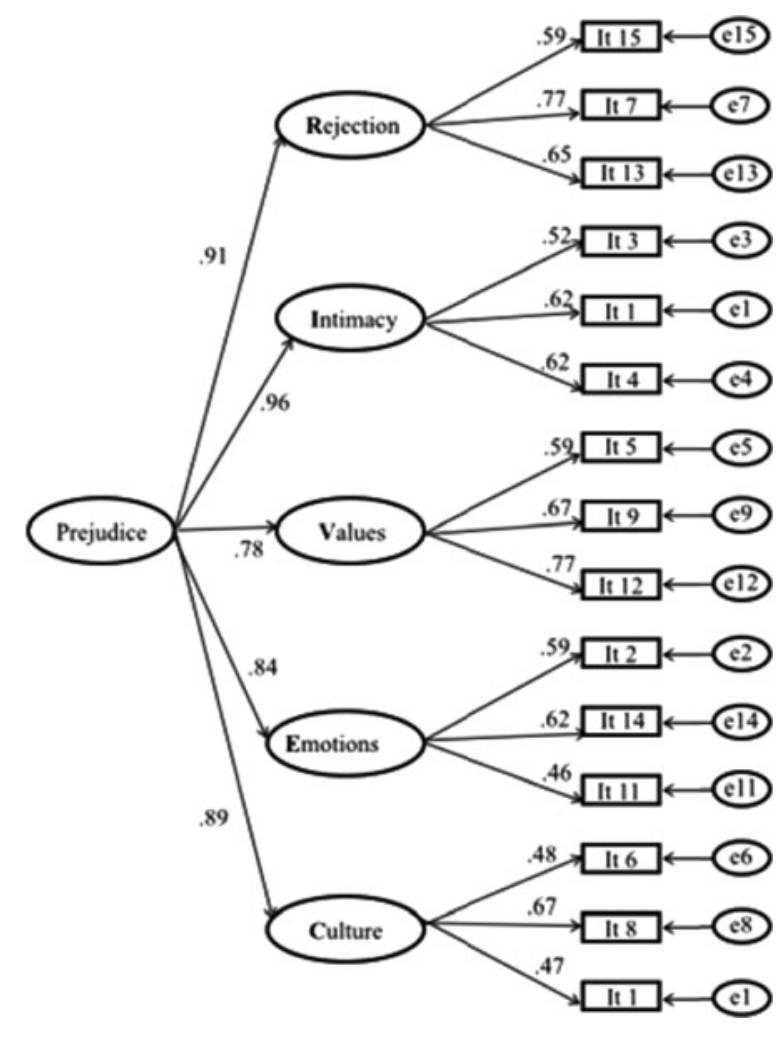

Figure 1

One second-order factor with five first-order factors model). Standardised solution with WLSMV (weighted least squares with mean and variance adjustment) estimation.

\section{Confirmatory Factor Analysis}

Model 1 was composed of two correlated second-order factors: blatant and subtle, with five first-order factors. The first one comprised rejection and intimacy factors and the second one comprised values, culture and emotions factors. The chi-squared $\left(\chi^{2}\right)$ statistic was significant; $\chi^{2} / d f=2.31$; CFI $=.90$; RMSEA $=.08$; and SRMR $=.06$ values were within the acceptable limits. The TLI (0.88) was slightly under the acceptable limits. The factor loading estimates were high (ranging from .45 to .94) and significant $(p<.05)$. The estimated correlation between both dimensions was extremely high $(\phi=.99)$.

In model 2 (second-order factor model with five firstorder factors; see Figure 1) we obtained a similar adjustment of the model to the data to that obtained with the 
Table 3

Model 2: Tests of Measurement Invariance (Multi-Group Analyses) of RIVEC Prejudice Scale Between Subsample 1 and Subsample 2, and Between Women and Men

\begin{tabular}{|c|c|c|c|c|c|c|c|c|}
\hline & $x^{2}$ & $d f$ & $\chi^{2} / d f$ & $\chi^{2}$ diff & RMSEA & SRMR & $\mathrm{CFI}$ & TLI \\
\hline \multicolumn{9}{|l|}{ Single group solutions } \\
\hline Subsample $1(n=236)$ & $195.20^{*}$ & 85 & 2.30 & & .074 & .058 & .90 & .88 \\
\hline Subsample $2(n=235)$ & $187.72^{*}$ & 85 & 2.21 & & .072 & .065 & .89 & .87 \\
\hline \multicolumn{9}{|l|}{ Tests of measurement Invariance } \\
\hline Equal form & $382.92 *$ & 170 & 2.25 & & .052 & .058 & .90 & .87 \\
\hline Equal measurement weights & $398.82^{*}$ & 180 & 2.22 & $15.90^{* *}$ & .051 & .062 & $.89^{(1)}$ & .88 \\
\hline Equal structural weights & 399.93* & 184 & 2.17 & $1.12^{* *}$ & .050 & .062 & $.89^{(1)}$ & .88 \\
\hline Equal structural covariances & $400.74 *$ & 185 & 2.17 & $0.81^{* *}$ & .050 & .064 & $.89^{(1)}$ & .88 \\
\hline Equal structural residuals & $413.16^{*}$ & 190 & 2.16 & $2.61^{* *}$ & .049 & .065 & $.89^{(1)}$ & .88 \\
\hline Equal measurement residuals & 419.73* & 205 & 2.05 & $16.32^{* *}$ & .047 & .066 & $.90^{(1)}$ & .89 \\
\hline \multicolumn{9}{|l|}{ Single group solutions } \\
\hline Women $(n=233)$ & $249.59 *$ & 85 & 2.94 & & 0.091 & & 0.93 & 0.92 \\
\hline Men $(n=238)$ & $264.63^{*}$ & 85 & 3.11 & & 0.094 & & 0.91 & 0.89 \\
\hline \multicolumn{9}{|l|}{ Tests of measurement Invariance } \\
\hline Equal form & $429.45^{*}$ & 170 & 2.53 & & 0.057 & 0.063 & 0.88 & 0.85 \\
\hline Equal measurement weights & $441.30^{*}$ & 180 & 2.45 & $11.86^{* *}$ & 0.056 & 0.064 & $0.88^{(1)}$ & 0.85 \\
\hline Equal structural weights & $443.18^{*}$ & 184 & 2.41 & $1.88^{* *}$ & 0.055 & 0.064 & $0.88^{(1)}$ & 0.86 \\
\hline Equal structural covariances & $443.20^{*}$ & 185 & 2.40 & $0.02^{* *}$ & 0.055 & 0.064 & $0.88^{(1)}$ & 0.86 \\
\hline Equal structural residuals & $447.33^{*}$ & 190 & 2.35 & $4.13^{* *}$ & 0.054 & 0.064 & $0.88^{(1)}$ & 0.86 \\
\hline Equal measurement residuals & $473.10^{*}$ & 205 & 2.31 & $25.77^{*}$ & 0.053 & 0.067 & $0.87^{(1)}$ & 0.87 \\
\hline
\end{tabular}

Note: ML estimation for single and multiple-groups solutions (tests of measurement invariance); $\chi^{2}$ diff: nested, $\chi^{2}$ difference ${ }^{*} p<.05$; ** $p .05 ;(1) \mathrm{CFI} \leq 0.01$

previous model. The $\chi^{2}$ was significant (likely due to the sample size); the ratio $\chi^{2} / d f=2.30$, SRMR (.058), RMSEA (.074) and CFI (.90) values were within the acceptable limits. The TLI (.88) was slightly under the acceptable limits. All factor loadings were significant $(p<.05)$, with high or medium-high values. All second-order factor loadings were within admissible levels and above 0.78, suggesting that all components are good expressions of general prejudice.

In estimating model 2 with a multigroup strategy (sample 1, $n=236$; sample 2, $n=235$ ), most of the GOF statistics of the unconstrained model were good. The $\chi^{2}$ was significant (likely because of the sample size); the ratio (2.25), SRMR (.058), and RMSEA (.052) revealed a relatively good model fit; CFI (.90) and TLI (.87) suggested an acceptable fit to the data (Table 3). All factor loadings were significant $(p<.05)$, attaining high or mediumhigh values. The nested model constraints (measurement weights, structural weights, structural covariances, structural residuals, and measurement residuals) presented an acceptable fit to the data, similar to the unconstrained model. The results of the factorial invariance test related to the hypothesis of equal parameters (Table 3 ) were consistent with three levels of factorial invariance that are of more interest to be contrasted (Byrne, 2013): measurement weights, $p=.10$; structural weights, $p=.89$; structural covariances, $p=.37$; structural residuals, $p=.76$. Although factorial invariance of measurement residuals was not established $(p=.38)$, this would not be a determinant in this case as the numbers of participants of the compared groups were similar and the samples proceed from the same population (Lubke \& Dolan, 2003). In addition, according to Byrne (2013), the hypothesis that is of most interest to contrast are measurement weights, structural weights, and structural covariances. The CFI and TLI changes $(\leq 0.01)$ were consistent with the results related to the hypothesised contrast of different invariance levels (Table 3).

The results related to the multigroup analyses across gender groups (female: $n=233$; male: $n=238$ ) were similar to those obtained in the previous multigroup analyses. Most of the GOF statistics of the unconstrained model were good. The $\chi^{2}$ was significant (likely due to the sample size), and the ratio (2.53), SRMR (0.063), and RMSEA (0.057) revealed a relatively good model fit; however, CFI (.88) and TLI (.85) were below the expected limits (Table 3). All factor loadings were significant $(p<$ .05 ), attaining high or medium-high values. The nested models (measurement weights, structural weights, structural covariances, structural residuals, and measurement residuals) presented an acceptable fit to the data, similar to the unconstrained model. The results of the factorial invariance test related to the hypothesis of equal parameters were consistent with three of the four levels of factorial invariance (measurement weights, $p=.30$; structural weights, $p=.76$; structural covariances, $p=.90$; and structural residuals, $p=.55$ ). The hypothesis related to the equivalence of parameters for the measurement residuals was not confirmed $(p=.04)$. The CFI and TLI changes $(\leq 0.01)$ were consistent with the results related to the hypothesised contrast of different invariance levels (Table 3 ). Considering Meredith's (1993) categorisation for the testing invariance of prejudice measurement and structure, the results across samples 1 and 2 (cross-validation) were 'strict' and the consistency across genders was 'strong'. 
Table 4

Summary of Hierarchical Regression Analysis (Backward Method) for Variables Predicting Prejudice RIVEC Scale scores $(N=471)$

\begin{tabular}{|c|c|c|c|c|}
\hline Models ${ }^{1}$ & $\begin{array}{l}\text { Independent } \\
\text { variables }^{2}\end{array}$ & $\begin{array}{l}\text { Standardised } \\
\text { coefficients } b^{a}\end{array}$ & $R^{2}$ & $F$ \\
\hline \multirow[t]{8}{*}{ Step 1} & $\mathrm{~B}_{0}$ (constant) & $23.18^{* * *}$ & & \\
\hline & Gender & $-0.01^{+}$ & & \\
\hline & Age & $0.13^{* *}$ & & \\
\hline & $\mathrm{RB}$ & $-0.01^{+}$ & .35 & $34.04^{* * *}$ \\
\hline & EMM & $-0.01^{+}$ & & \\
\hline & $\mathrm{EL}$ & $-0.16^{* * *}$ & & \\
\hline & PSC & $0.19^{* * *}$ & & \\
\hline & IR & $0.46^{* * *}$ & & \\
\hline \multirow[t]{7}{*}{ Step 2} & $\mathrm{~B}_{0}$ (constant) & $23.12^{* * *}$ & & \\
\hline & Age & $0.13^{* *}$ & & \\
\hline & $\mathrm{RB}$ & $-0.01^{+}$ & & \\
\hline & EMM & $-0.01^{+}$ & .35 & $39.79^{* * *}$ \\
\hline & EL & $-0.16^{* * *}$ & & \\
\hline & PSC & $0.19^{* * *}$ & & \\
\hline & IR & $0.46^{* * *}$ & & \\
\hline \multirow[t]{6}{*}{ Step 3} & $\mathrm{~B}_{0}$ (constant) & $23.03^{* * *}$ & & \\
\hline & Age & $0.13^{* *}$ & & \\
\hline & EMM & $-0.01^{+}$ & .35 & $47.84^{* * * *}$ \\
\hline & EL & $-0.16^{* * *}$ & & \\
\hline & PSC & $0.19^{* * *}$ & & \\
\hline & IR & $0.46^{* * *}$ & & \\
\hline \multirow[t]{5}{*}{ Step 4} & $\mathrm{~B}_{0}$ (constant) & $22.99 * * *$ & & \\
\hline & Age & $0.13^{* *}$ & & \\
\hline & EL & $-0.15^{* * *}$ & .34 & $59.90^{* * *}$ \\
\hline & PSC & $0.19^{* * *}$ & & \\
\hline & IR & $0.46^{* * *}$ & & \\
\hline
\end{tabular}

Note: ${ }^{1}$ Dependent variable: prejudice; ${ }^{2} \mathrm{IV}$ : independent variables in the model $(\mathrm{RB}=$ religious belief; $\mathrm{EMM}=$ ethnic minority membership; EL = household educational level; PSC $=$ politic self-categorisation; IR $=$ immigrants' rights)

$+p<.10 ;{ }^{*} p<.05 ; * * p<.01 ; * * * p<.001$

According to the suggested typology based on the five component scores, the participants' level of prejudice expression towards the target group (Bolivians) could be classified as follows: absent (0 components), 17.6\%; low (1 component), 22.1\%; low-medium (2 components), 15.1\%; medium-high (3 components), 15.7\%; high (4 components), 15.1\%; and extreme (5 components), $14.4 \%$.

\section{Hierarchical Regression Analysis for RIVEC Prejudice Scale}

Table 4 presents the hierarchical regression analyses (backward method). The final model (Step 4) considers four of the seven initial variables: age, political self-categorisation, household educational level, and immigrants' rights; $F(4,456)=59.90, p<.001)$. The model fit was not affected by the progressive elimination of the variables in the equation $\left(R^{2}\right.$ adjusted $\left.=0.34\right)$. Considering the standardised coefficients, it is noted that the immigrants' rights variable is the one that has the highest weight in explaining the prejudice score (dependent variable), followed by political self-categorisation, household educational level, and age $([z$ prejudice $]=0.08 \times[z$ age $]-1.05 \times[z$ household ed ucational level $]+2.41 \times[z$ political self-categorisation $]$ $+4.90 \times[z$ immigrants' rights $]$ ).

\section{Discussion}

This adapted version based on the five components of prejudice expression proposed by Pettigrew and Meertens (1995) confirms that the five-component structure (rejection, intimacy, values, emotions, and culture) enables the assessment of current prejudice - both its presence and absence - across its five dimensions, and the general intensity of expression. However, the new version of the scale does not differentiate blatantly prejudiced individuals from those with more subtle expressions of prejudice. The profile that the new scale provides is linked to the intensity of expressions of prejudice but not to the participants' characteristics. Estimates from model 1 (the model with two correlated first-order factors) suggest that it is not possible to make a real distinction between blatant and subtle prejudice, as the observed correlation between both entities is extremely high $(\phi=0.99)$. No evidence of discriminant validity has been found. Our data indicate that a single dimension underlies the prejudice construct. Model 2 , which separately considers the five domain components and an underlying general prejudice dimension, obtained an acceptable fit. The first-order factor loadings were similar to those obtained in the two-factor model, suggesting that item measurement capabilities were retained in this model. The second-order factor loadings were high for all components, indicating that a common prejudice dimension underlies the expression of all five components, with rejection, intimacy and culture the components most closely tied to overall prejudice. The results of the multigroup analyses confirmed the validity of the proposed prejudice structure and its equivalence between gender groups.

This adapted version based on the five components of prejudice expression proposed by Pettigrew and Meertens (1995), which is more streamlined and overcomes difficulties encountered in the original instrument, suggests that the five prejudice expression components proposed by the original authors (rejection, intimacy, values, culture, and emotions) do measure common prejudice as a general factor. These five components can be distinguished from one another by their degree of presence or absence, but they may not be regarded as representing two types of prejudice, at least as the original authors proposed (blatant: rejection and intimacy; subtle: values, culture, and emotions).

These components are expressed with varying levels of intensity depending on the subject and the context (the target group is considered part of the context). Since the study of Brewer and Miller (1984), we know that ingroup bias and negative emotions towards the outgroup arise when group membership is salient. The specific emotions of any group member towards the outgroup rest on their appraisal of the intergroup context (Mackie, Devos, \& Smith, 2000, p. 613). No behaviour is isolated from the social context. The importance of context was first noted by Lewin and subsequently by nearly all developments in social psychology: 'Every psychological event depends 
upon the state of person and at the same time on the environment, although their relative importance is different in different cases' (Lewin, 1936, p. 12).

As the results have shown, expression of prejudice is not separable from the intergroup context in which it manifests, but neither is the person who manifests the prejudice. The Pettigrew and Meertens scale (2001) primarily considers the individual and appears to overlook the context. Their typology assumes that people belong to one of the three stereotyping categories-'Bigots', 'Subtles', and 'Equalitarians' - and that individuals behave and express prejudice invariably according to their typology. Pettigrew and Meertens equate the blatant and subtle expression of prejudice to a subject's prejudice typology ('Bigots', 'Subtles', 'Equalitarians', and 'Errors'), producing an inexplicable logical leap. According to Pettigrew and Meertens (2001), ' [ . . . ] Subtles have a distinctive attitudinal pattern that consistently falls between those of the Equalitarians and Bigots' (p. 306). The researchers add that:

we find this condition [if given the opportunity, Subtles should be as likely to respond negatively to minorities as the Bigots] to be the least convincing. [...] we hold that the Subtles, when ostensibly non-prejudicial reasons are available, will more closely resemble the Bigots in their views - but will not typically be as negative as the Bigots. (p. 306)

This assumption indicates that the influence of social context on the expression of prejudice is not as decisive as the individual factors. A person expresses prejudice in a variable manner highly influenced by the social context, observable according to the five components (rejection, intimacy, values, emotions, and culture). These expressions are indicated by continued absence or presence rather than categorised as blatant or subtle. According to Eagly and Diekman (2005, p. 31), 'it is insufficient to view prejudice solely as a rigid, generalized attitude toward a group'. Duckitt's (2001) conclusions based on empirical research are applicable to our results: these findings support the idea that individual worldviews are influenced by social environments:

... however, it is also plausible that individuals' direct experience of their social realities will powerfully influence their social worldviews. This suggests that particular social environments will be highly conductive to prejudice and others to tolerance and that these effects will occur primarily through social environments' impact on individuals' worldviews. (p. 91)

This idea suggests that the context is able to prevail over individual attitudinal disposition with regard to prejudice expression (LaPiere, 1934).

Related to the predicted capability of the sociodemographic and cultural variables, four of the seven variables included in the initial model (age, immigrants' rights, political self-categorisation, and household educational level) explain the overall measure of bias obtained through the RIVEC Prejudice Scale.
While the results published to date do not seem to be entirely consistent, there is a partial consensus of two variables that would be significant in predicting attitudes related to intergroup bias: social dominance (Asbrock, Sibley, \& Duckitt, 2010; Heaven \& Quintin, 2003; Sidanius, Pratto, \& Mitchell, 1994; Sidanius, Pratto, Van Laar, \& Levin, 2004) and right-wing political orientation (Altemeyer, 1981; Duckitt, \& Sibley, 2007). Although 'immigrants' rights' is not a direct measure of social dominance, it represents itself indirectly. In accordance with Sidanius et al. (1994), the theory of social dominance 'maintains that all complex social systems have a tendency to form group-based hierarchies or caste systems' (p. 152). Thus, when participants were asked whether they preferred that the rights of Bolivian immigrants in Chile be increased, maintained, reduced or limited, those who stood towards the pole of decreasing or revoking rights had higher levels of prejudice than those at the opposite pole.

Political self-categorisation was the second variable with most weight in explaining the extent of general bias. Participants with right-wing orientation registered the highest overall prejudice. These results are consistent with those obtained by Altemeyer (1981, 1998; see Duckitt, 1992, for a systematic review), who observed high expression of intergroup bias among those with a right-leaning or strong authoritarian component and a firm belief in submission to established authority and adherence to rules (Altemeyer, 1981).

The variable 'household educational level' stood at the third place in the four variables significantly explaining intergroup prejudice. The results showed that participants with higher levels of education manifest lower expression of prejudice. According to Jackman and Muha (1984), these results should be interpreted with caution because people with higher education levels have a better control of expression per se, expressing intergroup biases in a highly sophisticated manner, making it more difficult to detect the expression of intergroup bias. But this greater cognitive control of prejudice expression by people with higher levels of education was subsequently questioned by Wagner and Zick (1995). These results could be explained from the perspective of fear and threat. The reference group, Bolivian immigrants, is characterised by low education levels and access to low-skilled jobs. This may explain why people with a high educational level did not perceive Bolivians as a threatening group. Less educated Chileans, however, may be more inclined to perceive Bolivian immigrants as undesirable and dangerous competition, given the precariousness in which they find themselves.

The fourth and final variable presented that was significant in explaining intergroup bias was 'age'. According to the results, older people manifest higher expression of prejudice. These results are broadly consistent with current theoretical evidence (Radvansky, Copeland, \& von Hippel, 2010; Firebaugh \& Davis, 1988; Wilson, 1996). Although the relationship between age and expression of prejudice has been widely described, the reason for 
this relationship in not entirely clear. The results of this study are compatible with the possibility that adult people 'have more difficulty than younger adults in putting the brakes on their automatic prejudicial responses' (Stewart, von Hippel, \& Radvansky, 2009, p. 167); or, perhaps following the explanations of Schuman, Steeh, Bobo, and Krysan (1997), these people have been socialised in times of greater prejudice. The latter explanation is particularly pertinent since Chile seized the Antofagasta region from Bolivia in 1879, denying Bolivia a seaport; arguably, younger Chileans are more sympathetic to Bolivian antipathy. In addition, the older Chilean generation witnessed, during the military dictatorship (1973-1990), a major derogation of the rights of immigrants (with the lowest rate of immigration in Chilean history), which could inform greater expression of prejudice towards Bolivian immigrants.

Moreover, the resulting model did not incorporate the variables 'gender', 'ethnic minority membership', and 'religious belief', which may indicate that these variables do not provide additional meaningful information to the explanation of the prejudice construct, in this context.

Many Chileans native to the Antofagasta region have a close historical and consanguineous relationship with the Bolivian people. It could be hypothesised that the sharing of ethnicity might affect the expression of prejudice in some way, but the results do not realise any effect.

Most of the research related to gender and prejudice conducted with explicit measures has found greater racial prejudice expressed by men. However, these results have been reflected primarily in relation to the scale of social dominance (Backstrom \& Björklund, 2007). These results have not been consistent with those found with implicit measures. Ekehammar, Akrami, and Araya (2003) consistently found that by measuring prejudice with implicit measures, women expressed prejudice more strongly. In this study, no differences regarding the structure or the level of prejudice were observed regarding this variable.

Regarding the relationship between religious belief and prejudice, it is at the same time obvious and contradictory; contradictory, in that when many religions promote love and respect among each other, they also inspire tensions (e.g., the conflict between Catholics and Protestants in Northern Ireland, the attack on the Twin Towers in the United States in 2001 and the subsequent U.S. invasion of
Iraq, violence between Palestinians and Jews in the Middle East). Thus, 'religiously based prejudice and conflict are disturbingly evident in the world, as evidenced in almost daily news reports' (Hunsberger \& Jackson 2005, p. 807). Studies show that the strongest relationship between prejudice and religion is established when the reference groups are women or gay men, people with leftist or extreme leftist ideas, and with people of other religions with a strong element of religious fundamentalism (Hunsberger \& Jackson, 2005). The non-significant relationship between religion and prejudice in this study could be explained by the reference group (i.e., Bolivians).

The results of this study are limited in scope for the following reasons. To account for the intensity level of expression of prejudice, we added the number of components in which each individual obtained a high score $(\geq 8)$. Although it would have been advisable, prior to the addition of the components, to have weighted the strength of each of them according to the factor weights in the CFA, we decided to use the first strategy, with the aim of providing a simple way for computing the results. Another aspect is related to social desirability. Though strategies were considered in the research design to control social desirability on participants' answers, no statistical strategy was applied.

\section{Recommendations for Future Research}

There is no doubt that future research related to the RIVEC Prejudice Scale should focus on finding more validity evidence. This new scale should be tested with more representative transcultural samples and with different reference groups. Additionally, it would be interesting to evaluate the intensity with which the components of prejudice are expressed in different social contexts and with different prejudice reference groups. Convergent validity of the instrument should be confirmed by correlating with variables that are also related with prejudice expression and were not considered in our study, such as affective and cognitive components. Also, it is recommended to correlate the instrument punctuation with an indirect measure of prejudice, such as priming or a measure obtained with the Implicit Assocation Test (IAT). We also recommend a longitudinal evaluation in order to evaluate the stability of the scores along the time. 


\section{Appendix}

The Pettigrew and Meertens blatant and subtle prejudice items (original scale) and the proposed scale (RIVEC Prejudice Scale)

Original Scale

Threat And Rejection Items (Blatant Prejudice)

1. Turks have jobs that the Dutch should have (strongly agree to strongly disagree).

2. Most Turks living here who receive support from welfare could get along without if they tried (strongly agree to strongly disagree).

3. Dutch people and Turks can never be really comfortable with they are close friends (strongly agree to strongly disagree).

4. Most politicians in the Netherlands care too much about Turks and not enough about the average Dutch (strongly agree to strongly disagree).

5. Turks come from less able races and this explains why they are not as well off as most Dutch people (strongly agree to strongly disagree).

6. How different or similar do you think Turks living here are to other Dutch people like yourself - in how honest they are? (very different, somewhat different, somewhat similar, or very similar)

Intimacy Items (Blatant Prejudice)

1. Suppose that a child of yours had children with a person of very different colour and physical characteristics than your own. Do you think you will be very bothered, bothered, bothered a little, or not bothered at all, if your grandchildren did not physically resemble the people on your side of the family?

2. I would be willing to have sexual relations with a Turk (strongly agree to strongly disagree) $\left({ }^{*}\right)$.

3. I would not mind if a suitably qualified Turk was appointed as my boss (strongly agree to strongly disagree) $\left({ }^{*}\right)$.

4. I would not mind if a Turkish person who had a similar economic background as mine joined my close family by marriage (strongly agree to strongly disagree) $\left({ }^{*}\right)$.

Traditional Values Items (Subtle Prejudice)

1. Turks living here should not push themselves where they are not wanted (strongly agree to strongly disagree).

2. Many other groups have come to the Netherlands and overcome prejudice and worked their way up. Turks should do the same without any special favour (strongly agree to strongly disagree).

3. It is just a matter of some people not trying hard enough. If Turks only try harder they could be as well off as Dutch people (strongly agree to strongly disagree).

4. Turks living here teach their children values and skills different from those required to be successful in the Netherlands (strongly agree to strongly disagree).

Cultural Differences Items (Subtle Prejudice)

How different or similar do you think Turks living here are to other Dutch people like yourself (very different, somewhat different, somewhat similar, or very similar)

1. In the values that they teach their children?

2. In their religious beliefs or practices?

3. In their sexual values or sexual practices?

4. In the language that they speak?

Positive Emotions Items (Subtle Prejudice)

Have you ever felt the following ways about Turks and their families living here (very often, fairly often, not too often, or never)?

1. How often have you felt sympathy for Turks living here? (*)

2. How often have you felt admiration for Turks living here? (*)

\section{Proposed Scale**}

Threat And Rejection Items (Rejection)

Bolivians live worse than Chileans because they belong to a less able race.

2. Bolivian immigrants take jobs, housing and school places that should be filled by Chilean citizens

3. In general, Bolivians are people that you cannot trust.

\section{Intimacy Items (Intimacy)}

1. I do not think there is a difference between a Chilean good friend and a Bolivian good friend $\left({ }^{*}\right)$.

2. If I have to travel for work with a co-worker, I would prefer to travel with a Chilean than with a Bolivian.

3. I would not mind if a Bolivian person with a cultural level similar to mine married someone from my family $\left({ }^{*}\right)$.
Traditional Values Items (Values)

1. I perceive that Bolivians living in Chile do not understand the friendship values that we have in Chile.

2. The disadvantage of Bolivian immigrants using some services (apartment rentals, hospitals, etc.) is that they don't know how to respect the established norms and rules.

3. Bolivian immigrants don't have the ingrained value that we give to the family in Chile.

\section{Cultural Differences Items (Culture)}

1. If my son had a Bolivian classmate he will be enriched by recognizing different traditions and customs $\left({ }^{*}\right)$

2. The Bolivian children who go to school in Chile should assimilate more to the culture of our country than their culture.

3. If a Bolivian child goes to school in Chile he or she should be required to respect our cultural values and traditions $(*)$.

\section{Positive Emotions Items (Emotions)}

1. I admire Bolivian immigrants who come to Chile looking for better job opportunities (*).

2. In general, I feel sympathy for Bolivian immigrants who come to live in our country $\left(^{*}\right)$.

3. In general, I consider that the Bolivian people resident in Chile are friendly and educated $(*)$.

\section{$(*)$ : reversed scoring}

$(* *)$ : Correction instructions:

Item scoring: 1 to 5 ( 1 =absolutely disagree, 2 =disagree, $3=$ neither agree nor disagree, $4=$ agree, $5=$ absolutely agree).

Component scoring: (the absence/presence of prejudice in each component): Add the score of the three items per component. A raw score $\geq 8$ is evidence of the presence of prejudice expression in a particular component, which will then be scored with a 1 . A raw score $<8$ is evidence of the absence of prejudice expression in a particular component, which will thus be scored with a 0 .

Prejudice scoring (intensity of prejudice expression): Add the component results. $0=$ absence (absence of prejudice in any component), $1=$ low intensity (the presence of prejudice in one of five components), 2 = low-medium intensity (the presence of prejudice in two of five components), 3 = medium-high intensity (the presence of prejudice in three of five components), $4=$ high intensity (the presence of prejudice in four of five components), and $5=$ extreme intensity (the presence of prejudice in all five components). 


\section{References}

Allport, G.W. (1954). The nature of prejudice. Cambridge, MA: Addison-Wesley.

Altemeyer, B. (1981). Right-wing authoritiarianism. Winnipeg, Canada: University of Manitoba Press.

Altemeyer, B. (1998). The other 'authoritarian personality'. In L. Berkowitz (Ed.), Advances in experimental social psychology (vol. 30, pp. 47-92). Orlando, FL: Academic.

Arancibia, H., Ruiz, M.Á., Blanco, A., \& Cárdenas, M. (2016). New evidence of construct validity problems for Pettigrew and Meertens' (1995) Blatant and Subtle Prejudice Scale. Psychological Reports, 118, 544-564.

Asbrock, F., Sibley, C.G., \& Duckitt, J. (2010). Right-wing authoritarianism and social dominance orientation and the dimensions of generalized prejudice: A longitudinal test. European Journal of Personality, 24, 324-340.

Bäckström, M., \& Björklund, F. (2007). Structural modeling of generalized prejudice: The role of social dominance, authoritarianism, and empathy. Journal of Individual Differences, $28,10-17$.

Bobo, L.D., \& Fox, C. (2003). Race, racism, and discrimination: Bridging problems, methods, and theory in social psychological research. Social Psychology Quarterly, 66, 319332.

Brewer, M., \& Miller, N. (1984). Beyond the contact hypothesis: Theoretical perspectives on desegregation. In N. Miller \& M. Brewer (Eds.), Group in contact: The psychology of desegregation (pp. 281-302). Orlando, FL: Academic Press.

Brown, T.A. (2006). Confirmatory factor analysis for applied research. New York: Guilford Press.

Byrne, B.M. (2013). Structural equation modeling with Mplus: Basic concepts, applications, and programming. New York: Routledge.

Cárdenas, M.C. (2010). Forms of ethnic prejudice: Assessing the dimensionality of a Spanish language version of the Blatant and Subtle Prejudice Scale. Psicothema, 22, 118-124.

Coenders, M., Scheepers, P., Sniderman, P., \& Verbek, G. (2001). Blatant and subtle prejudice: Dimensions, determinants and consequences: Some comments on Pettigrew and Meertens. European Journal of Social Psychology 31, 281-297.

Crocker, J., \& Major, B. (1989). Social stigma and self-esteem: The self-protective properties of stigma. Psychological Review, 96, 608.

Dovidio, J.F. (2001). On the nature of contemporary prejudice: The third wave. Journal of Social Issues, 57, 829-849.

Devine, P.G., Monteith, M.J., Zuwerink, J.R., \& Elliot, A. (1991). Prejudice with and whitout compunction. Journal of Personality and Social Psychology, 60, 817-830.

Duckitt, J.H. (1992). Psychology and prejudice: A historical analysis and integrative framework. American Psychologist, 47, 1182-1193.

Duckitt, J. (2001). A dual-process cognitive-motivational theory of ideology and prejudice. Advances in Experimental Social Psychology, 33, 41-113.
Duckitt, J., \& Sibley, C.G. (2007). Right wing authoritarianism, social dominance orientation and the dimensions of generalized prejudice. European Journal of Personality, 21, 113-130.

Eagly, A.H., \& Diekman, A.B. (2005). What is the problem? Prejudice as an attitude-in-context. On the Nature of Prejudice, $50,19-35$.

Ekehammar, B., Akrami, N., \& Araya, T. (2003). Gender differences in implicit prejudice. Personality and Individual differences, 34, 1509-1523.

Espelt, E., Javaloy, F., \& Cornejo, J.M. (2006). Las escalas de prejuicio manifiesto y sutil: ?'una o dos dimensiones? Anales de Psicología, 22, 81-88.

Firebaugh, G., \& Davis, K. (1988). Trends in antiblack prejudice, 1972-1984: Region and cohort effects. American Journal of Sociology, 94, 251-272.

Fiske, S.T. (2012). Managing ambivalent prejudices smart-butcold and warm-but-dumb stereotypes. The Annals of the American Academy of Political and Social Science, 639, 33-48.

Gadermann, A.M., Guhn, M., \& Zumbo, B.D. (2012). Estimating ordinal reliability for Likert-type and ordinal item response data: A conceptual, empirical, and practical guide. Practical Assessment, Research \& Evaluation, 17, 1-13.

Gómez, A., \& Huici, C. (1999). Orientación política y racismo sutil y manifiesto: relaciones con la discriminación [Political orientation, subtle and blatant racism: The relations with discrimination]. Revista de Psicología Social, 14, 2-3.

Hamberger, J., \& Hewstone, M. (1997). Inter-ethnic contact as a predictor of blatant and subtle prejudice: Tests of a model in four West European nations. British Journal of Social Psychology, 36, 173-190.

Heaven, P.C., \& Quintin, D.S. (2003). Personality factors predict racial prejudice. Personality and Individual Differences, 34, 625-634.

Hightower, E. (1997). Psychosocial characteristics of subtle and blatant racists as compared to tolerant individuals. Journal of Clinical Psychology, 53, 369-374.

Hilton, J., \& von Hippel, W. (1996). Stereotypes. Annual Review of Psychology, 47, 237-271.

Hunsberger, B., \& Jackson, L.M. (2005). Religion, meaning, and prejudice. Journal of Social Issues, 61, 807-826.

Jackman, M.R., \& Muha, M.J. (1984). Education and intergroup attitudes: Moral enlightenment, superficial democratic commitment, or ideological refinement? American Sociological Review, 49, 751-769.

LaPiere, R.T. (1934). Attitudes vs. actions. Social Forces, 13, 230 237.

Lewin, I. (1936). Principles of topological psychology. New York: McGraw-Hill.

Lubke, G.H., \& Dolan, C.V. (2003). Can unequal residual variances across groups mask differences in residual means in the common factor model? Structural Equation Modeling, $10,175-192$.

Mackie, D., Devos, T., \& Smith, E. (2000). Intergroup emotions: Insights from a theoretically integrative approach. Journal of Personality and Social Psychology, 79, 602-616. 
Marsh, H.W., Hau, K.T., \& Wen, Z. (2004). In search of golden rules: Comment on hypothesis-testing approaches to setting cutoff values for fit indexes and dangers in overgeneralizing $\mathrm{Hu}$ and Bentler's (1999) findings. Structural Equation Modeling, 11, 320-341.

Mayor, B., Quinton, W.J., \& Schmader, T. (2003). Attributions to discrimination and self-esteem: Impact of group identification and situational ambiguity. Journal of Experimental Social Psychology, 39, 220-231.

Meertens, R.W., \& Pettigrew, T.F. (1997). Is subtle prejudice really prejudice? Public Opinion Quarterly, 61, 54-71.

Meredith, W. (1993). Measurement invariance, factor analysis, and factorial invariance. Psychometrika, 58, 525-543.

Nunnally, J.C., \& Bernstein, I.H. (1994). Psychometric theory (3rd. ed.). NewYork: McGraw-Hill.

Olaizola, J.H., Díaz, F.J.R., \& Ochoa, G.M. (2014). Comparing intergroup contact effects on blatant and subtle prejudice in adolescents: A multivariate multilevel model. Psicothema, $26,33-38$.

Operario, D., \& Fiske, S.T. (2001). Effects of trait dominance on powerholders' judgments of subordinates. Social Cognition, 19, 161-180.

Pettigrew, T.F., \& Meertens, R.W. (1995). Subtle and blatant prejudice in Western Europe. European Journal of Social Psychology, 25, 57-75.

Pettigrew, T.F., \& Meertens, R.W. (2001). In defense of the subtle prejudice concept: a retort. European Journal of Social Psychology, 31, 299-309.

Radvansky, G.A., Copeland, D.E., \& von Hippel, W. (2010). Stereotype activation, inhibition, and aging. Journal of Experimental Social Psychology, 46, 51-60.

Ratazzi, M., \& Volpato, C. (2003). Social desirability of subtle and blatant prejudice scales. Psychological Reports, 92, 241-250.

Rodríguez Díaz, F.J., Herrero Olaizola, J.B., Ovejero Bernal, A., \& Torres, A.V. (2009). New expressions of racism among young people in Spain: An adaptation of Meertens and Pettigrew (1992) Prejudice scale. Adolescence, 44, 1033-1043.

Rueda, J.F., \& Navas, M. (1996). Hacia una evaluación de las nuevas formas del prejuicio racial: las actitudes sutiles del racismo [Towards an evaluation of new forms of racial prejudice: The subtle attitudes of racism]. Revista de Psicología Social, 11, 131-149.

Russell, D.W. (2002). In search of underlying dimensions: The use (and abuse) of factor analysis. Personality and Social Psychology Bulletin, 28, 1629-1646.

Schreiber, J.B., Nora, A., Stage, F.K., Barlow, E.A., \& King, J. (2006). Reporting structural equation modelling and confirmatory factor analysis results: A review. The Journal of Educational Research, 99, 323-338.

Schuman, H., Steeh, C., Bobo, L., \& Krysan, M. (1997). Racial attitudes in America: Trends and interpretations (rev. ed.). Cambridge, MA: Harvard University Press.

Sherif, M. (1967). Group conflict and co-operation: Their social psychology. London: Routledge \& Kegan Paul.

Sidanius, J., Pratto, F., \& Mitchell, M. (1994). In-group identification, social dominance orientation, and differential intergroup social allocation. The Journal of Social Psychology, 134, 151-167.

Sidanius, J., Pratto, F., Van Laar, C., \& Levin, S. (2004). Social dominance theory: Its agenda and method. Political Psychology, 25, 845-880.

Sniderman, P.M. \& Tetlock, P.E. (1986). Symbolic racism: Problems of motive attribution in political debate. Journal of Social Issues, 42, 129-150.

Sniderman, P.M., Piazza, T., Tetlock, P.E., \& Kendrick, A. (1991). The new racism. American Journal of Political Science, 35, 423-447.

Stewart, B.D., von Hippel, W., \& Radvansky, G. A. (2009). Age, race, and implicit prejudice using process dissociation to separate the underlying components. Psychological Science, 20, 164-168.

Tajfel, H. (1982). Social psychology of intergroup relations. Annual Review of Psychology, 33, 1-39.

Villano, P. (1999). Anti-Semitic prejudice in adolescence: An Italian study on shared beliefs. Psychological Reports, 84, 13721378.

Wagner, U., \& Zick, A. (1995). The relation of formal education to ethnic prejudice: Its reliability, validity and explanation. European Journal of Social Psychology, 25, 41-56.

Wilson, T.C. (1996). Cohort and prejudice: Whites' attitudes toward Blacks, Hispanics, Jews and Asians. Public Opinion Quarterly, 60, 253-274.

Yoo, H.C., Steger, M.F., \& Lee, R.M. (2010). Validation of the subtle and blatant racism scale for Asian American college students (SABR-A ${ }^{2}$. Cultural Diversity and Ethnic Minority Psychology, 16, 323.

Yu, C.Y. (2002). Evaluating cutoff criteria of model fit indices for latent variable models with binary and continuous outcomes (Doctoral dissertation). University of California, CA. Retrieved from http://www.statmodel.com/ download/Yudissertation.pdf

Zick, A., Wagner, U., Van Dick, R., \& Petzel, T. (2001). Acculturation and prejudice in Germany: Majority and minority perspectives. Journal of Social Issues, 57, 541-557. 